\title{
Anthropogenic mercury sequestration in different soil types on the southeast coast of China
}

\author{
Haibo Zhang • Yuan Li • Yongming Luo • Peter Christie
}

Received: 25 June 2014 / Accepted: 7 January 2015

(C) Springer-Verlag Berlin Heidelberg 2015

\begin{abstract}
Purpose Soil is a major pool of anthropogenically emitted mercury $(\mathrm{Hg})$ and will in turn be a source of atmospheric $\mathrm{Hg}$ contamination. It was hypothesized that accumulation of anthropogenic $\mathrm{Hg}$ in the soil at a regional scale is associated with the amount of $\mathrm{Hg}$ emitted to the atmosphere and soil type. Materials and methods A total of 448 horizon samples were collected from the typical soil types of the Yangtze River Delta and Pearl River Delta. Titanium (Ti) was selected as a reference element to discriminate anthropogenic $\mathrm{Hg}$ from the $\mathrm{Hg}$ associated with pedogenic processes. Soil pools of anthropogenic $\mathrm{Hg}$ were quantified to show the difference in $\mathrm{Hg}$ sequestration among soil types and regions.

Results and discussion Soil pools of anthropogenic $\mathrm{Hg}$ ranged from 0.70 to $6971 \mathrm{~g} / \mathrm{ha}$ in the Yangtze River Delta (YRD) and from 35.81 to $13098.71 \mathrm{~g} / \mathrm{ha}$ in the Pearl River Delta (PRD). The estimated soil Hg pools were well correlated with the amounts of $\mathrm{Hg}$ emitted in these two regions. Soil properties, namely organic matter content, amorphous iron oxides, and cation exchange capacity, were significantly ( $\mathbf{p}<$ 0.01 ) and positively correlated with soil $\mathrm{Hg}$ accumulation. Meanwhile, soil organic matter was the most important factor to determine the depth distribution of $\mathrm{Hg}$ in soil profile of the
\end{abstract}

Responsible editor: Jean-Paul Schwitzguébel

Electronic supplementary material The online version of this article (doi:10.1007/s11368-015-1062-1) contains supplementary material, which is available to authorized users.

H. Zhang $\cdot$ Y. Li $\cdot$ Y. Luo $(\triangle)$

Key Laboratory of Coastal Zone Environmental Processes and Ecological Remediation, Yantai Institute of Coastal Zone Research, Chinese Academy of Sciences, Yantai 264003, China

e-mail:ymluo@yic.ac.cn

P. Christie

Nanjing Institute of Soil Science, Chinese Academy of Sciences,

Nanjing 210008, China majority of soils. Perudic Cambisols and Stagnic Anthrosols which contained higher content of amorphous iron oxides had the highest soil $\mathrm{Hg}$ pools, indicating the importance of amorphous iron oxides other than organic matter to the Hg retention in soil. Soil and soil horizons with low $\mathrm{pH}$ and high salinity did show a low accumulation of $\mathrm{Hg}$ probably due to the remobilization of $\mathrm{Hg}$ under such conditions.

Conclusions In addition to the amount of $\mathrm{Hg}$ emitted, soil types may be a major factor in controlling the sequestration of anthropogenic $\mathrm{Hg}$ in both regions. Stagnic Anthrosols are an important pool for retention of anthropogenic Hg.

Keywords Depth distribution - Soil pool - Soil profile . Mercury (Hg) · Stagnic Anthrosols

\section{Introduction}

Mercury (Hg) is a globally toxic pollutant and has been of wide public health concern during the past decades (Feng and Qiu 2008; Hammond 1971; Lin et al. 1997; Lin et al. 2012; Zhang and Wong 2007). Anthropogenic emissions are considered to be the main source of global $\mathrm{Hg}$ contamination and have been estimated to account for $2320 \mathrm{t}$ annually (Pirrone et al. 2010). China is currently the country with the highest anthropogenic $\mathrm{Hg}$ emissions (Lin et al. 2012). Streets et al. (2005) estimate that total Chinese emissions are 536 $( \pm 236) t$ of total mercury, slightly lower than estimated by Wu et al. (2006), $696( \pm 307) t$ annually. However, both studies indicate that smelting of nonferrous metals and coal combustion, the two dominant anthropogenic sources, together account for $80 \%$ of total $\mathrm{Hg}$ emissions. Wu et al. (2006) also report total $\mathrm{Hg}$ emissions in individual provinces for 1995 and 2003 and show that provinces located in southeast China have 
dramatically higher $\mathrm{Hg}$ emissions that are related to growing industrialization coal combustion with the rapid economic development in this region (Jiang et al. 2006).

Anthropogenic $\mathrm{Hg}$ can be introduced to and accumulate in soil by various pathways such as dry and wet deposition from the atmosphere, release from waste products, and application of fertilizers and pesticides containing $\mathrm{Hg}$. Atmospheric deposition is assumed to be the most important contribution. Luo et al. (2009) estimate that atmospheric sources contribute more than $60 \%$ of total $\mathrm{Hg}$ inputs to agricultural soils in China followed by fertilizers which account for $30.4 \%$. Besides being affected by anthropogenic sources, accumulation of $\mathrm{Hg}$ in soil also depends on soil properties such as soil organic matter (SOM) content, $\mathrm{pH}$, and cation exchange capacity (CEC) (Huang et al. 2011; Smith-Downey et al. 2010; Yang et al. 2007). It has been well known that $\mathrm{Hg}$ has a high affinity for organic matter in soil and sediment (Ravichandran 2004; Skyllberg et al. 2006; Wallschlager et al. 1998). Mercury therefore tends to be retained in soils although losses do occur by leaching and volatilization (Grigal 2002; Scholtz et al. 2003). However, loss rates are assumed to be fairly small, typically less than $1 \%$ of the soil pool per annum (Tipping et al. 2011b). Hence, the soil pool of anthropogenic Hg, expressed as mass per unit area to a chosen soil depth, provides a measure of cumulative pollutant inputs. Tipping et al. (2011a) have calculated the soil $\mathrm{Hg}$ pool to a depth of $15 \mathrm{~cm}$ in the UK, and the results suggest that local deposition plays an important role in determining the $\mathrm{Hg}$ concentrations of UK soils. Yin et al. (2009) estimate that a cumulative input of anthropogenic $\mathrm{Hg}$ reaches 317 to $515 \mathrm{~g} / \mathrm{ha}$ in the surrounding topsoil of secondary copper smelters, equivalent to the soil $\mathrm{Hg}$ pool of urban and industrial soils in the UK. The main objective of the present study was therefore to investigate the major factors that contribute to the cumulative content of anthropogenic Hg in the different soils of the Yangtze River Delta and Pearl River Delta regions. The two regions are the most economically developed areas on the southeast coast of China and have different climatic conditions and dominant soil types.

\section{Materials and methods}

\subsection{Description of the study areas}

The Yangtze River Delta (YRD) and the Pearl River Delta (PRD) are the two most economically prosperous regions in southeast China, with annual rates of increase of gross domestic product (GDP) of 13.5 and $15.8 \%$, respectively, in 2006 . These are higher than the $9.6 \%$ national average GDP growth rate.

The YRD lies in the northern part of the subtropical zone with an annual average temperature of $17{ }^{\circ} \mathrm{C}$ and annual average rainfall of $1072 \mathrm{~mm}$. The total area of the region is around $100,000 \mathrm{~km}^{2}$ and is mostly plain with only a small proportion of the upland in the west of the region. Udic Luvisols, Stagnic Anthrosols, and Aquic Cambisols are the dominant soil types in this region based on the FAO World Reference Base for Soil Resources (IUSS Working Group WRB 2006). Udic Luvisols are locally dominant in the uplands, and Stagnic Anthrosols have developed with long-term rice cultivation in the plain. Aquic Cambisols are distributed mainly in coastal areas and both sides of the Yangtze River and are primarily used for nonflooded crops such as vegetables and cotton. Other soil types of concern in this study are Udic Ferrisols and Perudic Cambisols.

The PRD is located on the southeast coast of China at the southern fringe of the subtropical zone. With a total land area of $25,000 \mathrm{~km}^{2}$ and a population of 42 million, it is the second most populous area in China and one of the most densely populated areas of the world. The climate is characterized by high humidity and temperatures, with an annual average precipitation of $1800 \mathrm{~mm}$ and annual average temperature of $22{ }^{\circ} \mathrm{C}$. The soil is highly weathered in highland areas and waterlogged in flat terrain. Udic Ferralsols, Stagnic Anthrosols, and Orthic Halosols are the dominant soil types (IUSS Working Group WRB 2006). Soil types of concern in this study are Anthric Entisols, Orthic Halosols, and Sandic Entisols. Soils in this region are acid to neutral, and the soil organic matter content is high in paddy fields and orchards but comparatively low in uncultivated land.

\subsection{Soil sampling and analytical methods}

A total of 448 horizon samples were collected from the study areas in December of 2006. Based on pedogenic features, 262 horizon samples were taken from the 60 main soil profiles of the areas. A further 186 horizon samples were taken from the surface $(0-20 \mathrm{~cm})$ and subsurface $(20-40 \mathrm{~cm})$ depths of the 83 soil cores which were situated in the surrounding areas of the 60 main soil profiles. Detailed information on the sampling sites is shown in Table S1 (Electronic Supplementary Material). The samples were air-dried at room temperature for several days, screened through a 2-mm sieve, and then stored in glass bottles prior to analysis. In order to determine the concentration of $\mathrm{Hg}$ and other mineral elements in the samples, the soil samples were ground and passed through a $0.149-\mathrm{mm}$ sieve before digestion. Total $\mathrm{Hg}$ in the soil was determined using the GB/T 17136-1997 method (SEPAC 1997). Briefly, $1.0 \mathrm{~g}$ of sieved soil was digested with $10-\mathrm{mL}$ mixed concentrated acids $\left(\mathrm{HNO}_{3} / \mathrm{H}_{2} \mathrm{SO}_{4}=1: 1(v / v)\right)$ and $10-\mathrm{mL} 0.13 \mathrm{M} \mathrm{KMnO}_{4}$ solution on an electric hot plate at $90{ }^{\circ} \mathrm{C}$ for $1 \mathrm{~h}$. The $\mathrm{Hg}$ concentration was determined using an atomic fluorescence spectrometer equipped with a flow injection system (AFS-930, Vital Co., Beijing). The total concentrations of $\mathrm{Ti}$ and $\mathrm{Fe}$ in the soil were determined by inductively coupled plasma atomic emission spectroscopy (ICP- 
AES; PerkinElmer 3300 DV) after 0.5-g sieved soil was digested with $1 \mathrm{~mL} 60 \%$ perchloric acid, $8 \mathrm{~mL} 40 \%$ hydrofluoric acid, and $17 \mathrm{~mL}$ concentrated nitric acid. Soil properties ( $\mathrm{pH}$, SOM, CEC, soil bulk density, humic acid, and iron oxides) were analyzed based on the methods of $\mathrm{Lu}$ (2000). Briefly, soil pH was measured by $\mathrm{pH}$ meter (LP115, Mettler-Toledo, Switzerland). SOM contents were measured by wet oxidation using $\mathrm{K}_{2} \mathrm{Cr}_{2} \mathrm{O}_{7}$. CEC was measured by the ammonium acetate method. Soil bulk density was measured by the gravimetric method after collecting undisturbed soil using a cutting ring. Humic acid was determined by a spectrophotometric method after isolating humic acid from the soil. Iron oxides were extracted using dithionite-citratebicarbonate (DCB) solution and acid (pH 3.0) ammonium oxalate extraction separately, representative of the crystal iron oxides and the amorphous iron oxides, respectively. The extracted iron was analyzed by ICP-AES. For quality control purposes, certified reference materials (CRMs, supplied by the National Research Center for CRMs, Beijing) were used as the external standards and analyzed with each batch of the samples in a proportion of $10 \%$. As a result, the geometric mean of the Hg concentration in the CRM soil (GBW07403) was determined to be $58.4 \mathrm{mg} / \mathrm{kg}(n=18)$ with a range of $55-$ $63 \mathrm{mg} / \mathrm{kg}$, which is consistent with the certified value of $60.4 \mathrm{mg} / \mathrm{kg}$.

\subsection{Calculation of anthropogenic $\mathrm{Hg}$ concentration in the horizon soil samples}

The measured Hg concentration in soil contains endogenous and exogenous $\mathrm{Hg}$. Endogenous $\mathrm{Hg}$ is derived mainly from mineral weathering during the process of soil development, and exogenous $\mathrm{Hg}$ is mainly from the inputs of various anthropogenic sources. Calculation of anthropogenic $\mathrm{Hg}$ concentration in the horizon soil samples is mainly based on the methods of Zhang et al. (2007) and Zhang and Luo (2011). The anthropogenic $\mathrm{Hg}\left([\mathrm{Hg}]_{\mathrm{exo}}\right)$ was estimated by

$$
[\mathrm{Hg}]_{\mathrm{exo}}=[\mathrm{Hg}]_{\mathrm{total}}-[\mathrm{Hg}]_{\mathrm{endo}}
$$

where $[\mathrm{Hg}]_{\text {total }}$ is the measured total $\mathrm{Hg}$ concentration $(\mathrm{mg} / \mathrm{kg})$ and $[\mathrm{Hg}]_{\text {endo }}$ is the concentration $(\mathrm{mg} / \mathrm{kg})$ sourced from mineral weathering in the soil. The latter was estimated by

$[\mathrm{Hg}]_{\text {endo }}=0.015[\mathrm{Ti}]+0.004$

where [Ti] is the measured total Ti concentration $(\mathrm{mg} / \mathrm{kg})$ at each soil depth, 0.015 is the coefficient, and 0.004 is the constant; the standard error of the coefficient was 0.0048 . All the coefficients were derived from the linear regression between $\mathrm{Hg}$ and $\mathrm{Ti}$ concentration values of the bottom soil layers. The linear regression function for the prediction of endogenous $\mathrm{Hg}$ was fitted at a significance level of 0.01 .

\subsection{Calculation of soil pools of anthropogenic $\mathrm{Hg}$}

The soil pools of anthropogenic $\mathrm{Hg}$ are the amounts of anthropogenic $\mathrm{Hg}$ sequestered by the soil. This is not restricted to the surface soil. Some of the anthropogenic $\mathrm{Hg}$ can migrate downward and accumulate in deeper layers or even the subsoil. Hence, the soil pool of anthropogenic $\mathrm{Hg}(P[\mathrm{Hg}], \mathrm{g} / \mathrm{ha})$ is the sum of anthropogenic $\mathrm{Hg}$ amounts in each pedogenic horizon $\left(P_{i}[\mathrm{Hg}], \mathrm{g} / \mathrm{ha}\right)$ and can be calculated by

$P[\mathrm{Hg}]=\sum_{i=1}^{n} P_{i}[\mathrm{Hg}]$

$P_{i}[\mathrm{Hg}]=[\mathrm{Hg}]_{\mathrm{exo}} \times \rho \times h$

where $\rho$ is the soil density $\left(\mathrm{g} / \mathrm{cm}^{3}\right)$ and $h$ is the soil depth $(\mathrm{cm})$.

\subsection{Statistical analysis}

Statistical analysis was performed using the SPSS for Windows v. 13.0 software package. Multiple comparison of the $\mathrm{Hg}$ concentration among the different genetic horizons of each soil type was conducted by one-way analysis of variance, and pairs of mean values were compared by least significant difference (LSD) at the $5 \%$ level. Regression analysis between the $\mathrm{Hg}$ concentration and soil properties (CEC, soil organic matter, humic acid, and iron oxides) of the topsoil was performed to present the main factors contributing to the retention of anthropogenic $\mathrm{Hg}$ in the soils.

\section{Results and discussion}

\subsection{Total $\mathrm{Hg}$ concentration in the different soil types}

The soil Hg concentration in the different soil types of the two regions is shown in Table 1. The highest average concentration of $\mathrm{Hg}$ was observed in the Orthic Halosols, followed by Anthric Entisols, both of which were sampled from the Pearl River Delta. In addition, the Stagnic Anthrosols that are widely distributed as paddy soils in both study regions also showed relatively high $\mathrm{Hg}$ concentrations. As shown in Tables 1 and 2, $\mathrm{Hg}$ concentrations in the topsoil of the Stagnic Anthrosols were similar in both regions although the average $\mathrm{Hg}$ concentration of the topsoil of the whole region was slightly higher in the Pearl River Delta. Aquic Cambisols developed from alluvial deposits of the Yangtze River and usually used for vegetable production had lower Hg concentrations than the Stagnic Anthrosols. Compared to the soils in the plain regions, soil 


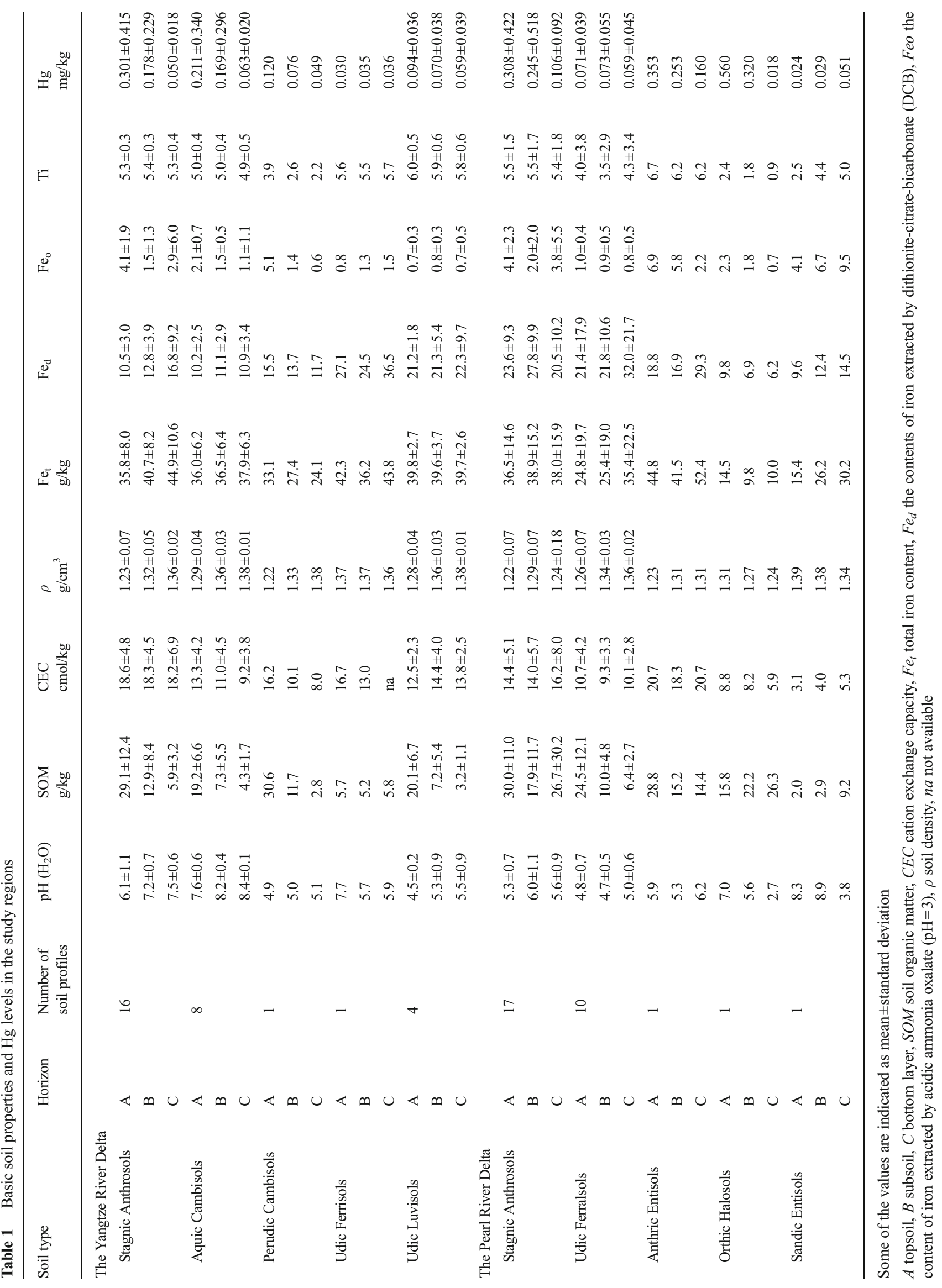


Table 2 Comparison of the $\mathrm{Hg}$ concentrations in the topsoils of the Yangtze River Delta (YRD) and Pearl River Delta (PRD) with other regions

\begin{tabular}{|c|c|c|c|c|c|}
\hline \multirow[t]{2}{*}{ Study region } & \multirow[t]{2}{*}{ Number } & \multicolumn{3}{|c|}{ Soil $\mathrm{Hg}$ content $(\mathrm{mg} / \mathrm{kg})$} & \multirow[t]{2}{*}{ Reference } \\
\hline & & Mean & Median & Range & \\
\hline The YRD & 41 & 0.261 & 0.160 & $0.054-1.78$ & This study \\
\hline The PRD & 100 & 0.311 & 0.200 & $0.028-1.91$ & This study \\
\hline Jiangsu Province & 231 & 0.100 & - & $0.006-2.76$ & Shi et al. 2013 \\
\hline Zhejiang Province & 311 & 0.110 & - & $0.112-1.95$ & Shi et al. 2013 \\
\hline Zhangjiagang County, Jiangsu Province & 547 & 0.140 & & $0.004-1.51$ & Huang et al. 2011 \\
\hline The PRD & 591 & 0.278 & 0.181 & $0.0167-3.32$ & Chen et al. 2012 \\
\hline Wuchuan, Guizhou Province & 16 & - & - & $0.33-320$ & Qiu et al. 2006 \\
\hline UK rural & 898 & 0.126 & 0.095 & $0.035-0.365$ & Tipping et al. 2011a \\
\hline Conterminous USA & 486 & 0.078 & - & - & Burt et al. 2003 \\
\hline Chinese Soil Standard & Background & & 0.15 & & SEPAC 1995 \\
\hline Chinese Soil Standard & Second level & & $0.30,0.60^{\mathrm{a}}$ & & SEPAC 1995 \\
\hline
\end{tabular}

${ }^{\mathrm{a}}$ For soil with $\mathrm{pH}>7.5$

types developed in the uplands such as Udic Ferrisols, Udic Luvisols, and Udic Ferralsols all had lower concentrations of soil Hg. The lowest average Hg concentration was observed in Sandic Entisols which is located in the estuary of the PRD region and influenced by marine water frequently. Therefore, in addition to the low content of soil organic matter in the Sandic Entisols (Table 1), the low concentration of $\mathrm{Hg}$ in the Sandic Entisols might be partially owing to the high soil salinity (data not shown) which enhance the solubility of $\mathrm{Hg}$ by forming $\mathrm{Hg}(\mathrm{II})$-chloride complexes $\left(\mathrm{HgCl}_{2}\right)$.

The measured topsoil $\mathrm{Hg}$ concentrations in both regions were generally higher than other reported values. As shown in Table 2, the average soil $\mathrm{Hg}$ concentration in the Yangtze River Delta was $0.261 \mathrm{mg} / \mathrm{kg}$, over twice the values for Jiangsu and Zhejiang provinces reported by Shi et al. (2013). The average soil Hg concentration of the Pearl River Delta was $0.311 \mathrm{mg} / \mathrm{kg}$, slightly higher than that reported by Chen et al. (2012) although the highest concentration was lower in the present study. The soil $\mathrm{Hg}$ concentrations of the two regions were also higher than those reported in the UK (Tipping et al. 2011a) and the conterminous USA (Burt et al. 2003). When using the Chinese soil standard as a benchmark (SEPAC 1995), the average Hg concentration in the Yangtze River Delta was higher than the background level, but the average Hg concentration in the Pearl River Delta was even higher than the second level of the standard, indicating potential risks to the local soil ecosystem.

\subsection{Depth distribution of Hg in typical soil types}

Some typical soil profiles were selected to present the depth distribution of soil Hg concentration (Fig. 1). The depth distributions of soil $\mathrm{Hg}$ concentration varied greatly between the two regions and among the soil types. In the case of Stagnic Anthrosols which was distributed widely in both regions, a dramatic decrease in soil $\mathrm{Hg}$ concentration occurred from the subsoil to bottom layer in the YRD region, while slight change occurred from topsoil to bottom layer in the same soil type in the PRD region. This trend is also supported by average horizontal concentration of the soil type in Table 1 . The $\mathrm{Hg}$ concentration ratio of $\mathrm{A} / \mathrm{B} / \mathrm{C}(\mathrm{A}, \mathrm{B}$, and $\mathrm{C}$ indicates topsoil, subsoil, and bottom layer, respectively) in the Stagnic Anthrosols of the Yangtze River Delta was 6.0:3.6:1 based on the data of Table 1 and was 2.9:2.3:1 for the Pearl River Delta. Multiple comparisons among the pedogenic horizons of the Stagnic Anthrosols also show that the $\mathrm{Hg}$ concentrations in the topsoil and subsoil were significantly $(p<0.05)$ higher than those in the bottom layers in the Yangtze River Delta, but there was no significant difference among the horizons in the Stagnic Anthrosols of the Pearl River Delta. Correspondingly, the depth distribution of SOM content in the YRD soil was much different to the PRD soil as shown in Table 1. The highest SOM content occurred in the topsoil and decreased dramatically with depth in the YRD soil; in contrast, no significant difference could be observed among the different horizons of the PRD soil. This implied that the depth distribution of $\mathrm{Hg}$ in the Stagnic Anthrosols was mainly determined by soil organic matter content. Meanwhile, lower soil $\mathrm{pH}$ and higher rainfall in the PRD region tended to enhance the mobilization of $\mathrm{Hg}$ from topsoil to bottom layer (Huang et al. 2011). In addition to the Stagnic Anthrosols, depth distributions of $\mathrm{Hg}$ in Aquic Cambisols, Perudic Cambisols, Udic Ferrisols, Udic Luvisols, Anthric Entisols, and Sandic Entisols were all associated with SOM content, 


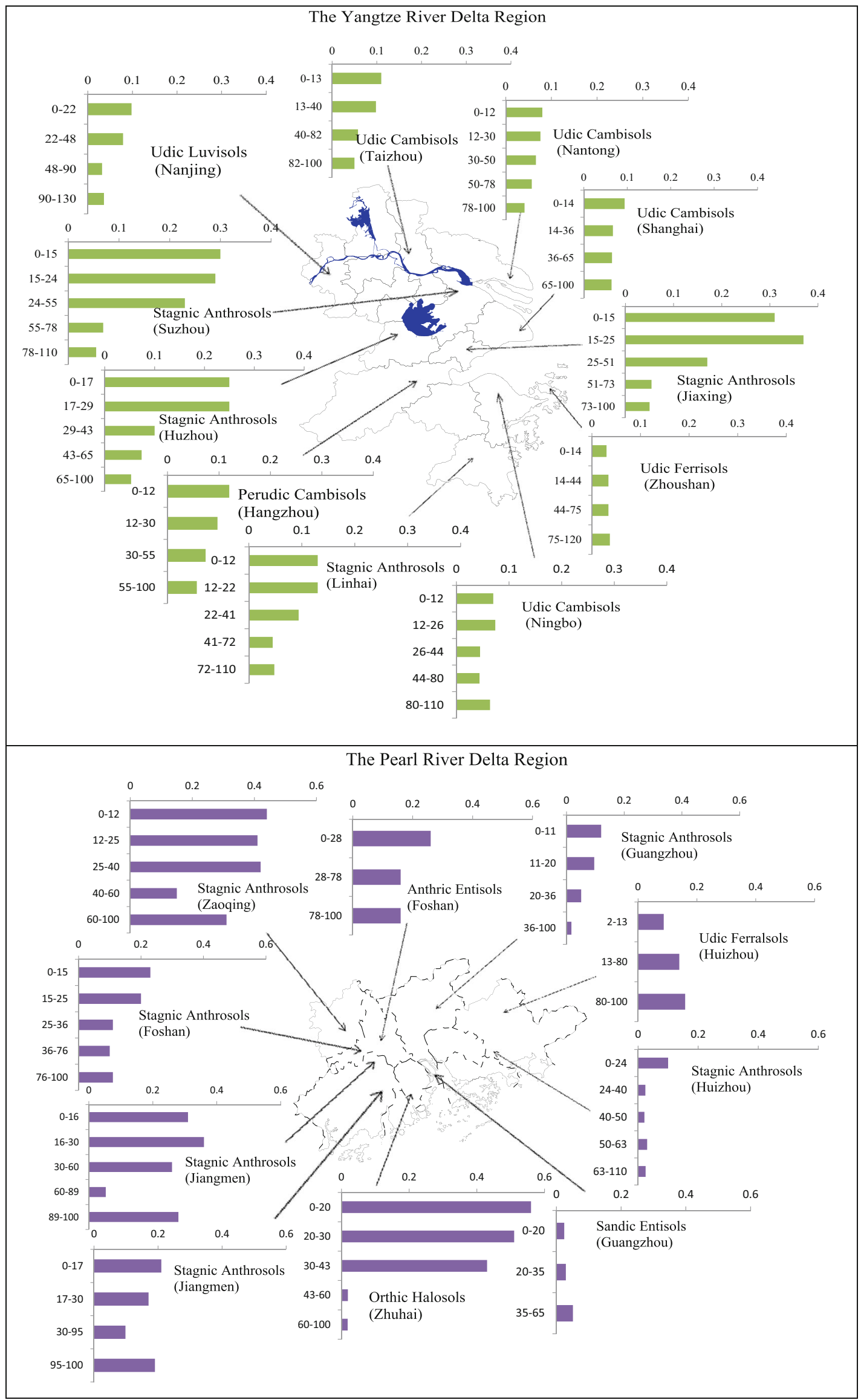


Fig. 1 Depth distribution of measured soil $\mathrm{Hg}$ concentrations in typical soil profiles. Text in plate indicates the names of soil types; text in parenthesis indicates the name of the sampling area

although small variation of $\mathrm{Hg}$ concentration in the profile of these soils was observed.

Depth distribution of $\mathrm{Hg}$ in the Orthic Halosols was very different from the other soil types. The typical soil profile of the Orthic Halosols was collected from the land where there was a saltmarsh prior to cultivation in the PRD. The topsoil of the Orthic Halosols had values up to $56 \mathrm{mg} / \mathrm{kg}$ and changed gradually from the topsoil to the third layer. A sharp decrease occurred from the third layer to the fourth layer as shown in Fig. 1. The depth distribution of $\mathrm{Hg}$ concentration in this soil type was associated with the $\mathrm{pH}$ value rather than SOM content, especially the extremely low concentration of $\mathrm{Hg}$ corresponding to the extremely low $\mathrm{pH}(\mathrm{pH}<3)$ in the bottom layers. This was probably due to the increase of solubility of the $\mathrm{Hg}$ organic complex under low $\mathrm{pH}$ condition. Ravichandran (2004) has summarized the conditional stability constant $(K)$ of $\mathrm{Hg}$ organic complexes from the literature, in which the $K$ value is usually lower than $10^{10}$ at low $\mathrm{pH}(\mathrm{pH}$ $<5$ ), while the $K$ value is as high as $10^{28.5}$ at $\mathrm{pH}$ of 8 .

In contrast to the decrease of $\mathrm{Hg}$ with depth in most soils, the depth distribution of $\mathrm{Hg}$ increased with depth in the Udic Ferralsols although SOM content of the soil decreased from topsoil to bottom layer (Fig. 1 and Table 1). Mercury remobilization could explain the lower concentration of $\mathrm{Hg}$ in the topsoil of the Udic Ferralsols. Hg remobilization can occur after the dissolution or erosion of $\mathrm{Hg}$-bearing phases (such as iron oxides) under temporal reducing condition (Grimaldi et al. 2008).

\subsection{Soil pools of anthropogenic $\mathrm{Hg}$}

Soil pools of anthropogenic $\mathrm{Hg}$ at a depth of $100 \mathrm{~cm}$ ranged from 0.70 to $6971.36 \mathrm{~g} / \mathrm{ha}$ in the Yangtze River Delta, lower than that in the Pearl River Delta which ranged from 35.8 to 13,098.7 $\mathrm{g} / \mathrm{ha}$. The soil $\mathrm{Hg}$ pool was further illustrated by cumulative frequency distribution curves. As shown in Fig. 2, the inflection point was determined at 838.4 and $925.3 \mathrm{~g} / \mathrm{ha}$ for the soil $\mathrm{Hg}$ pool to a depth of $100 \mathrm{~cm}$ in the Yangtze and Pearl River Deltas, respectively. These two values did reflect the 79 and $75 \%$ percentiles, respectively. For the soil $\mathrm{Hg}$ pool to a depth of $40 \mathrm{~cm}$, the inflection point was 670.9 and $839.2 \mathrm{~g} / \mathrm{ha}$, reflecting the 76 and $71 \%$ percentiles, respectively. The value beyond the inflection point usually implies that the sampling sites might be contaminated by some specific sources in addition to atmospheric precipitation. Therefore, these data were not included in the calculation of the average pool of the whole region (Zhang et al. 2007).

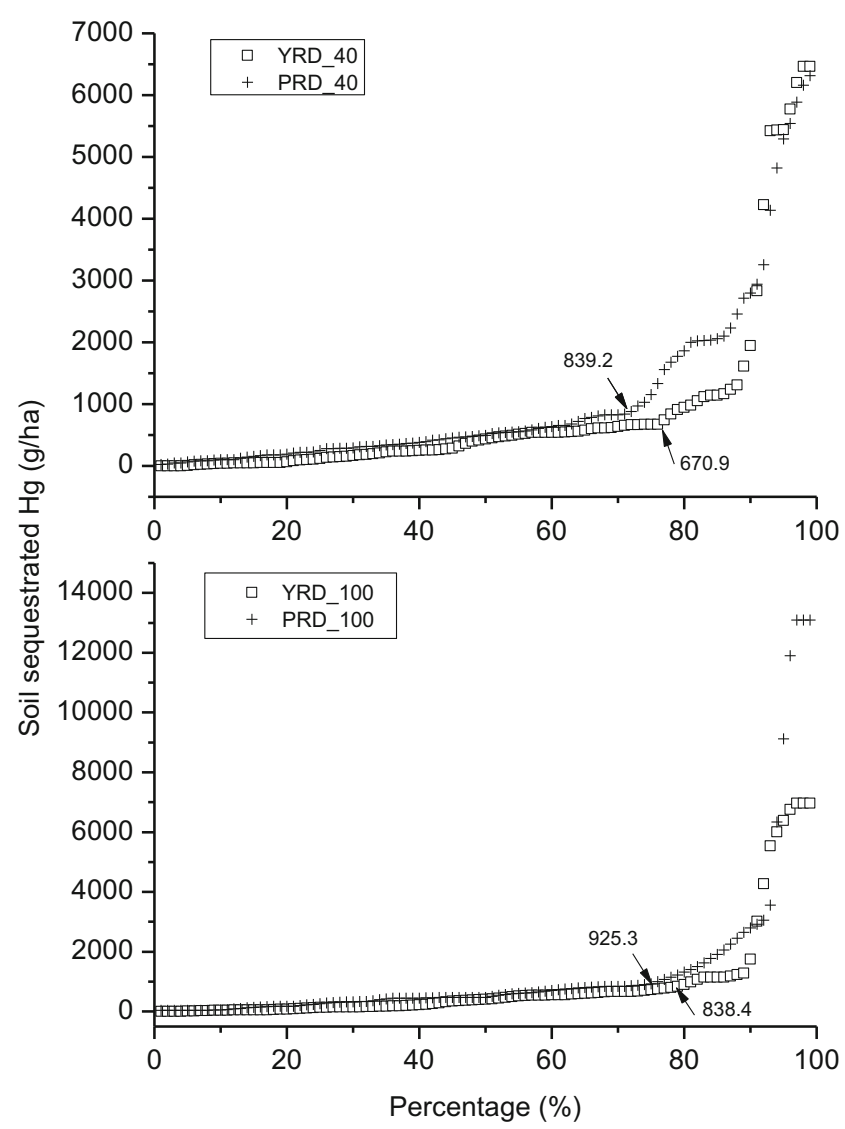

Fig. 2 Cumulative frequency distribution curves showing the data distribution of the calculated soil $\mathrm{Hg}$ pool for depths of 40 and $100 \mathrm{~cm}$. YRD 40 and PRD_40 indicate the soil $\mathrm{Hg}$ pool in the top 40-cm soil of the two regions, respectively; YRD 100 and $P R D \quad 100$ indicate the soil $\mathrm{Hg}$ pool in the whole soil profile of the Yangtze River Delta $(Y R D)$ and Pearl River Delta $(P R D)$, respectively

The differences in soil pools of anthropogenic $\mathrm{Hg}$ between the two regions were correlated to their $\mathrm{Hg}$ emissions as estimated by Cheng et al. (2009) and Zheng et al. (2011). The annual emission of $\mathrm{Hg}$ was estimated at $3.38 \mathrm{~g} / \mathrm{ha}$ in the Yangtze River Delta and $4.15 \mathrm{~g} / \mathrm{ha}$ in the Pearl River Delta (Table 3). In terms of the average soil Hg pool of the whole region, the emission ratio (0.81) between the Yangtze and Pearl River Deltas was quite similar to the ratio of the soil Hg pool (0.71). This implies that atmospheric deposition from localized sources did account for most of the soil $\mathrm{Hg}$ pool. The soil pool of anthropogenic $\mathrm{Hg}$ was very different among the different soil types. As shown in Table 3, Perudic Cambisols of the Yangtze River Delta had the highest soil Hg pool followed by Stagnic Anthrosols of the Pearl River Delta. The former developed in high mountains with high humidity and soil organic matter contents (Table 1), but the latter developed from long-term flooded rice cultivation. The humid and reducing conditions would facilitate the sequestration of anthropogenic Hg in the soils (Rothenberg and Feng 2012; Schuster 1991). 
Table 3 The soil Hg pool vs. Hg emission in the Yangtze River Delta (YRD) and Pearl River Delta (PRD) regions

\begin{tabular}{lccc}
\hline Soil type & \multicolumn{2}{c}{ Amount } & \multirow{2}{*}{ YRD/PRD ratio } \\
\cline { 2 - 3 } & YRD & PRD & \\
\cline { 1 - 2 } Average anthropogenic Hg emission in the whole region \\
\multicolumn{2}{c}{ Annual emission $(\mathrm{g} / \mathrm{ha}$ year) } \\
a & 3.38 & 4.15 & 0.81 \\
Average soil pool of Hg $(\mathrm{g} / \mathrm{ha})^{\mathrm{b}}$ & & & \\
Whole region & 310.5 & 438.8 & 0.71 \\
Stagnic Anthrosols & 467.9 & 475.7 & 0.90 \\
Aquic Cambisols & 119.2 & na & na \\
Perudic Cambisols & 530.4 & na & na \\
Udic Luvisols & 222.5 & na & na \\
Udic Ferralsols & na & 378.9 & na \\
\hline
\end{tabular}

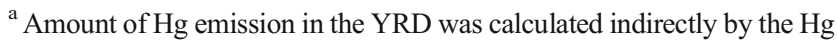
emission data from coal combustion of the region with a conversion factor of 2.7 (Wu et al. 2006; Cheng et al. 2009), while that of the PRD was calculated directly by the total $\mathrm{Hg}$ emission data from various anthropogenic sources (Zheng et al. 2011)

${ }^{\mathrm{b}}$ Outliers were not included in the calculation of the average soil pool of $\mathrm{Hg}$

\subsection{Influence of soil properties}

Linear regression analysis was performed to show the relationships between soil $\mathrm{Hg}$ concentrations and soil properties (Fig. 3). The data were selected based on $\mathrm{Hg}$ concentrations $<$ $0.4 \mathrm{mg} / \mathrm{kg}$ in the topsoil of the two regions. Hence, all the selected data reflected the absence of severe contamination at the sites in addition to atmospheric deposition. As shown in Fig. 3, significant $(p<0.01)$ positive correlations were found between the soil $\mathrm{Hg}$ concentrations and soil properties (SOM, humic acid, CEC, and amorphous iron oxides).

The amount of $\mathrm{Hg}$ binding in the soil depended on the sequestration of anthropogenic $\mathrm{Hg}$ in soil. There are several mechanisms to govern the binding of $\mathrm{Hg}$ in the soils, including nonspecifically adsorbed, specifically adsorbed, chelated, and precipitated (Schuster 1991). The significant correlation between $\mathrm{Hg}$ concentration and SOM, humic acids, CEC, and amorphous iron oxides suggested that chelated with humic substance and specifically adsorbed to the hydrous ferric oxides (HFO) might be the dominant mechanisms of Hg sequestration in soils of the YRD and the PRD. Mercury exhibits a great affinity for organic matter in soils by forming complexes with reduced sulfur groups (Skyllberg et al. 2006;
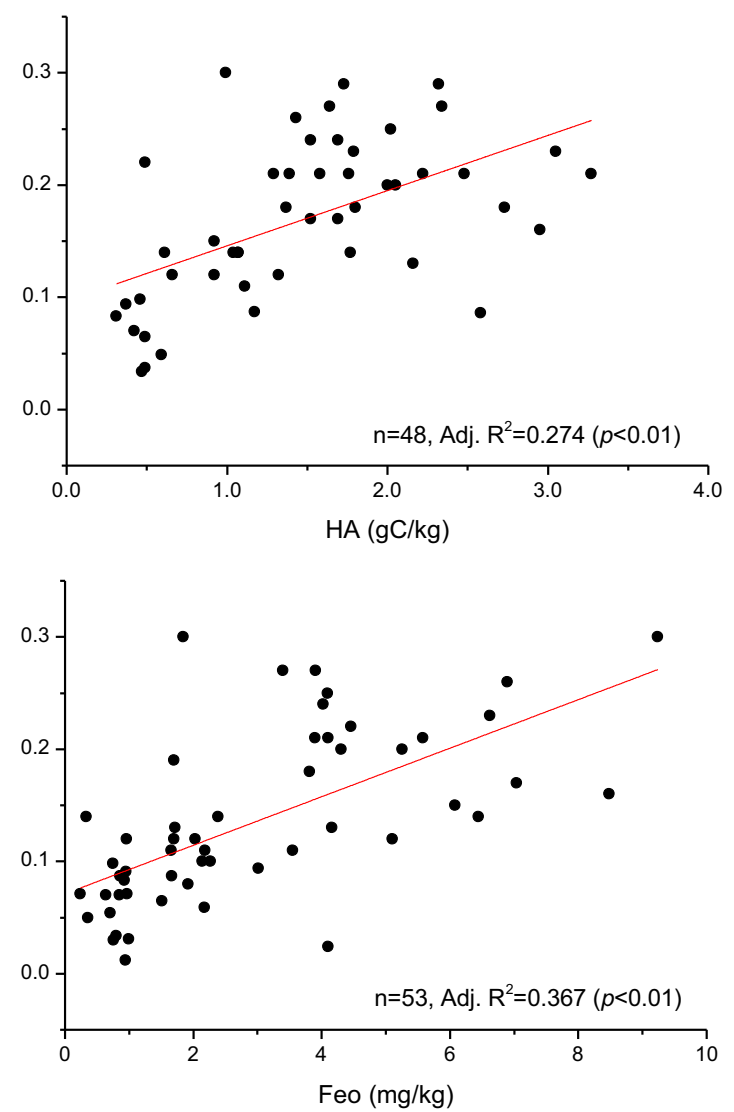

Fig. 3 Linear regression between the measured $\mathrm{Hg}$ concentrations and topsoil properties. SOM, HA, CEC, and Feo indicate soil organic matter, humic acid, cation exchange capacity, and acidic ammonium oxalate $(\mathrm{pH}=3)$ extractable iron, respectively 
Wallschlager et al. 1998). Humic acids (HAs) are major constituents of soil organic matter, containing complex mixtures of many different acids including carboxyl and phenolate groups. Therefore, the humic acids could form stable complexes with Hg in soil. Zhang et al. (2009) have reported a higher adsorption capacity and lower desorption of $\mathrm{Hg}^{2+}$ by humic acids than by fulvic acids. The reason might be attributed to the chemisorption capacity of humic acids, but not to fulvic acids (Wallschlager et al. 1996). Gu et al. (2011) reported that strong interactions can be observed between reduced HAs and $\operatorname{Hg}(0)$ under anoxic environment, and $\operatorname{Hg}(0)$ is the major speciation of atmospheric $\mathrm{Hg}$ which accumulates in topsoil through dry and wet deposition.

The specific adsorption of $\mathrm{Hg}$ on the hydrous ferric oxides could be explained by the concept of surface complexation (Schuster 1991). Liang et al. (2013) have compared the adsorption capacity for $\mathrm{Hg}^{2+}$ between $\mathrm{HFO}$ and goethite and found that the maximum $\mathrm{Hg}^{2+}$ adsorption $\left(S_{\max }\right)$ was higher for HFO due to its higher specific surface area. The mechanisms for the adsorption of $\mathrm{Hg}$ by HFO include the formation of ternary surface complexes and surface precipitation at high sorbate/sorbent ratio (Tiffreau et al. 1995). Therefore, the Perudic Cambisols and Stagnic Anthrosols which contained a relatively higher amorphous iron oxides content in the soils had a relatively higher soil $\mathrm{Hg}$ pools than other soil 3).

\section{Conclusions}

The measured Hg concentrations in the topsoils of the Yangtze River Delta and Pearl River Delta ranged from 0.054 to $1.78 \mathrm{mg} / \mathrm{kg}$ and from 0.028 to $1.91 \mathrm{mg} / \mathrm{kg}$, respectively. The difference in soil $\mathrm{Hg}$ between the two regions was associated with the amount emitted as well as soil properties. In the case of soil properties, soil organic matter, in particular of humic acid, was supposed to be the dominant factor to influence the spatial distribution and depth distribution of soil $\mathrm{Hg}$. Meanwhile, amorphous iron oxides (e.g., HFO) enhanced retention of $\mathrm{Hg}$ in the soils by forming surface complexes. This could be reflected from the higher soil $\mathrm{Hg}$ pools of Stagnic Anthrosols and Perudic Cambisols which had higher content of amorphous iron oxides as well. In addition, the soil that is widely distributed in the coastal zone of the PRD and characterized by low $\mathrm{pH}$ and high salinity had a low soil $\mathrm{Hg}$ pool in general as a result of high remobilization of soil $\mathrm{Hg}$ under such conditions.

Acknowledgments The authors are grateful for financial support from the Key Research Program of the Chinese Academy of Sciences (KZZDEW-14) and the National Natural Science Foundation of China (NSFC) (41230858, 41371313).

\section{References}

Burt R, Wilson MA, Mays MD, Lee CW (2003) Major and trace elements of selected pedons in the USA. J Environ Qual 32(6):2109-2121

Chen LG, Xu ZC, Ding XY, Zhang WD, Huang YM, Fan RF, Sun JR, Liu M, Qian DL, Feng YB (2012) Spatial trend and pollution assessment of total mercury and methylmercury pollution in the Pearl River Delta soil, South China. Chemosphere 88(5):612-619

Cheng K, Xue ZG, Zhang ZQ, Li H, Yi P, Wang YH, Xu YX (2009) Emission and control of air pollutants in major industries of Yangtze Delta. Environ Sci Technol (China) 32(9):120-123

Feng XB, Qiu GL (2008) Mercury pollution in Guizhou, Southwestern China - an overview. Sci Total Environ 400(1-3):227-237

Grigal DF (2002) Inputs and outputs of mercury from terrestrial watersheds: a review. Environ Rev 10(1):1-39

Grimaldi C, Grimaldi M, Guedron S (2008) Mercury distribution in tropical soil profiles related to origin of mercury and soil processes. Sci Total Environ 401(1-3):121-129

Gu BH, Bian YR, Miller CL, Dong WM, Jiang X, Liang LY (2011) Mercury reduction and complexation by natural organic matter in anoxic environments. P Natl Acad Sci USA 108(4):1479-1483

Hammond AL (1971) Mercury in environment — natural and human factors. Science 171(3973):788-789

Huang BA, Wang M, Yan LX, Sun WX, Zhao YC, Shi XZ, Weindorf DC (2011) Accumulation, transfer, and environmental risk of soil mercury in a rapidly industrializing region of the Yangtze River Delta, China. J Soils Sediments 11(4):607-618

IUSS Working Group WRB (2006) World Reference Base for Soil Resouces. $2^{\text {nd }}$ edition. World Soil Resources Reports No. 103. FAO, Rome, $128 \mathrm{p}$

Jiang GB, Shi JB, Feng XB (2006) Mercury pollution in China. Environ Sci Technol 40(12):3672-3678

Liang P, Li YC, Zhang C, Wu SC, Cui HJ, Yu S, Wong MH (2013) Effects of salinity and humic acid on the sorption of $\mathrm{Hg}$ on $\mathrm{Fe}$ and Mn hydroxides. J Hazard Mater 244:322-328

Lin YH, Guo MX, Gan WM (1997) Mercury pollution from small gold mines in China. Water Air Soil Poll 97(3-4):233-239

Lin Y, Vogt R, Larssen T (2012) Environmental mercury in China: a review. Environ Toxicol Chem 31(11):2431-2444

Lu R (2000) Analytical methods for soil and agricultural chemistry (In Chinese). China Agricultural Science and Technology Press, Beijing

Luo L, Ma Y, Zhang S, Wei D, Zhu YG (2009) An inventory of trace element inputs to agricultural soils in China. J Environ Manage 90(8):2524-2530

Pirrone N, Cinnirella S, Feng X, Finkelman RB, Friedli HR, Leaner J, Mason R, Mukherjee AB, Stracher GB, Streets DG, Telmer K (2010) Global mercury emissions to the atmosphere from anthropogenic and natural sources. Atmos Chem Phys 10(13):5951-5964

Qiu GL, Feng XB, Wang SF, Shang LH (2006) Environmental contamination of mercury from $\mathrm{Hg}$-mining areas in Wuchuan, northeastern Guizhou, China. Environ Pollut 142:549-558

Ravichandran M (2004) Interactions between mercury and dissolved organic matter - a review. Chemosphere 55:319-331

Rothenberg SE, Feng XB (2012) Mercury cycling in a flooded rice paddy. J Geophys Res-Biogeo 117, G03003

Scholtz MT, Van Heyst BJ, Schroeder W (2003) Modelling of mercury emissions from background soils. Sci Total Environ 304(1-3):185207

Schuster E (1991) The behavior of mercury in the soil with special emphasis on complexation and adsorption processes - a review of the literature. Water Air Soil Pollut 56:667-680

Shi JB, Meng M, Shao JJ, Zhang KG, Zhang QH, Jiang GB (2013) Spatial distribution of mercury in topsoil from five regions of China. Environ Sci Pollut Res 20(3):1756-1761 
Skyllberg U, Bloom PR, Qian J, Lin CM, Bleam WF (2006) Complexation of mercury(II) in soil organic matter: EXAFS evidence for linear two-coordination with reduced sulfur groups. Environ Sci Technol 40(13):4174-4180

Smith-Downey NV, Sunderland EM, Jacob DJ (2010) Anthropogenic impacts on global storage and emissions of mercury from terrestrial soils: insights from a new global model. J Geophys Res-Biogeo 115, G03008

State Environment Protection Administration of China (SEPAC) (1995) Environmental quality standards for soils (GB 5618-1995). Available at: http://english.mep.gov.cn/standards_reports/standards/ Soil/Quality_Standard3/200710/W020070313485587994018.pdf

State Environment Protection Administration of China (SEPAC) (1997) Soil quality - determination of total mercury-cold atomic absorption spectrophotometer (GB/T 17136-1997)

Streets DG, Hao JM, Wu Y, Jiang JK, Chan M, Tian HZ, Feng XB (2005) Anthropogenic mercury emissions in China. Atmos Environ 39(40): 7789-7806

Tiffreau C, Lutzenkirchen J, Behra P (1995) Modeling the adsorption of mercury(II) on (hydr)oxides.1. Amorphous iron-oxide and alphaquartz. J Colloid Interface Sci 172:82-93

Tipping E, Poskitt JM, Lawlor AJ, Wadsworth RA, Norris DA, Hall JR (2011a) Mercury in United Kingdom topsoils; concentrations, pools, and critical limit exceedances. Environ Pollut 159(12):3721-3729

Tipping E, Wadsworth RA, Norris DA, Hall JR, Ilyin I (2011b) Longterm mercury dynamics in UK soils. Environ Pollut 159(12):34743483

Wallschlager D, Desai MVM, Wilken RD (1996) The role of humic substances in the aqueous mobilization of mercury from contaminated floodplain soils. Water Air Soil Pollut 90(3-4):507-520
Wallschlager D, Desai MVM, Spengler M, Windmoller CC, Wilken RD (1998) How humic substances dominate mercury geochemistry in contaminated floodplain soils and sediments. J Environ Qual 27(5): 1044-1054

Wu Y, Wang SX, Streets DG, Hao JM, Chan M, Jiang JK (2006) Trends in anthropogenic mercury emissions in China from 1995 to 2003. Environ Sci Technol 40(17):5312-5318

Yang YK, Zhang C, Shi XJ, Lin T, Wang DY (2007) Effect of organic matter and $\mathrm{pH}$ on mercury release from soils. J Environ Sci-China 19(11):1349-1354

Yin XB, Yao CX, Song J, Li ZB, Zhang CB, Qian W, Bi D, Li CX, Teng Y, Wu LH, Wan HD, Luo YM (2009) Mercury contamination in vicinity of secondary copper smelters in Fuyang, Zhejiang Province, China: levels and contamination in topsoils. Environ Pollut 157(6): $1787-1793$

Zhang HB, Luo YM (2011) Endogenous and exogenous lead in soils of Yangtze River Delta region, China: identified by lead isotopic compositions and multi-elemental approaches. Environ Earth Sci 62(5): $1109-1115$

Zhang L, Wong MH (2007) Environmental mercury contamination in China: sources and impacts. Environ Int 33(1):108-121

Zhang HB, Luo YM, Wong MH, Zhao QG, Zhang GL (2007) Defining the geochemical baseline: a case of Hong Kong soils. Environ Geol 52(5):843-851

Zhang J, Dai JL, Wang RQ, Li FS, Wang WX (2009) Adsorption and desorption of divalent mercury $(\mathrm{Hg} 2+)$ on humic acids and fulvic acids extracted from typical soils in China. Colloid Surface A 335(1-3):194-201

Zheng JY, Ou JM, Mo ZW, Yin SS (2011) Mercury emission inventory and its spatial characteristics in the Pearl River Delta region, China. Sci Total Environ 412:214-222 